Research Article

\title{
Preparation of Portland Cement with Gold Ore Tailings
}

\author{
Qiang Wang, Geng Yao, Xiangnan Zhu, Junxiang Wang, Peng Wu, and Xianjun Lyu $(\mathbb{D}$ \\ College of Chemical and Environmental Engineering, Shandong University of Science and Technology, Qingdao 266590, China \\ Correspondence should be addressed to Xianjun Lyu; lu_xianjun@163.com
}

Received 2 February 2019; Revised 23 March 2019; Accepted 9 April 2019; Published 6 May 2019

Academic Editor: H. P. S. Abdul Khalil

Copyright (c) 2019 Qiang Wang et al. This is an open access article distributed under the Creative Commons Attribution License, which permits unrestricted use, distribution, and reproduction in any medium, provided the original work is properly cited.

\begin{abstract}
The disposal of gold ore tailings (GTs) has been a very difficult problem for a long time. Thus, this study explored a new approach to the management of GTs by preparing Portland cement. Physical properties, reaction mechanisms, and hydration product types of cement prepared with GTs (C-GTs) and ordinary Portland cement (C-SS) were compared. X-ray diffraction (XRD), thermogravimetric (TG), and scanning electron microscope energy-dispersive spectroscopy (SEM-EDS) analysis techniques were used to study the mineralogical phases of the clinker and raw materials, hydration product types, and microtopography. The consistency, setting time, flexural strength and compressive strength values of the cement samples (C-GTs and C-SS), and burnability of the raw materials were also studied. The burnability analysis indicated that GTs provided a higher reactivity. The XRD results showed that the clinker phases of the C-GTs were $\mathrm{C}_{3} \mathrm{~S}, \mathrm{C}_{2} \mathrm{~S}, \mathrm{C}_{3} \mathrm{~A}$, and $\mathrm{C}_{4} \mathrm{AF}$. The XRD, TG, and SEM-EDS results showed that the hydration products were flaky calcium hydroxide, rod-shaped ettringite, and granular C-S-H gels. Its compressive strength and flexural strength were, respectively, $30.4 \mathrm{MPa}$ and $6.1 \mathrm{MPa}$ at the curing age of 3 days and $59.1 \mathrm{MPa}$ and $9.8 \mathrm{MPa}$ at the curing age of 28 days, which were slightly higher than those of the C-SS. Furthermore, the results showed that the consistency, initial setting time, and final setting time for the two kinds of cement were similar, which further suggested that GTs could be used to prepare Portland cement.
\end{abstract}

\section{Introduction}

Ordinary Portland cement has become an indispensable building material in the construction industry with the rapid development of industrialization $[1,2]$. Cement production in China reached 2.316 billion tons in 2017 [3]. Large quantities of natural materials such as limestone, bauxite, clay, sandstone, and gypsum have been consumed in the cement industry.

Previous studies showed that some solid wastes could be used to prepare ordinary Portland cement, with physical properties such as the consistency, setting time, flexural strength, and compressive strength of cement prepared with solid wastes similar to those of ordinary Portland cement. Huang et al. [4] prepared a cement clinker with municipal sewage sludge and found that the flexural strength and compressive strength of the cement sample at a curing age of 28 days were greater than $6.5 \mathrm{MPa}$ and $42.5 \mathrm{MPa}$, respectively. Young and Yang [5] synthesized cement clinkers with different proportions of iron ore tailings (0-20 wt.\%) added to the raw materials instead of clay. Their investigation indicated that the addition of $10 \%$ iron ore tailings did not change the mineralogical phases $\left(\mathrm{C}_{3} \mathrm{~S}, \mathrm{C}_{2} \mathrm{~S}\right.$, $\mathrm{C}_{3} \mathrm{~A}$, and $\mathrm{C}_{4} \mathrm{AF}$ ) of the clinker. Moreover, the initial setting time and final setting time of the cement were $132 \mathrm{~min}$ and $185 \mathrm{~min}$, respectively, and the compressive strength of the cement reached $52.3 \mathrm{MPa}$ at the curing age of 28 days, which were in accordance with ordinary Portland cement. The application of ladle furnace slag from steelworks to cement clinker was studied by Vilaplana et al. [6]. They showed the possibility of incorporating $39.2 \mathrm{wt} . \%$ slag into the raw material of cement. Although the initial setting time of the calcined cement was 1.6 times higher than that of 52.5 grade cement as a result of the amount of $\mathrm{MgO}$, the compressive strength reached $54.0 \mathrm{MPa}$ at the curing age of 28 days. The overall properties of the cement met the requirements of cement grade 42.5R according to the Chinese standard (GB/ 175-2015), which indicated that using ladle furnace slag in 
raw cement materials could reduce the consumption of natural resources. Additionally, some investigations revealed that the appropriate addition of solid wastes to the raw materials for cement could also promote cement burnability and reduce the burning temperature. Luo et al. [7] introduced iron ore tailings as a substitute for clay in the raw materials to prepare cement clinker and showed that the burnability of the raw materials that included iron ore tailings was better than that of the raw materials without tailings because of the high content of alumina. Furthermore, there was no obvious difference in the physical and mechanical performances of the two cement clinkers. $\mathrm{Li}$ et al. [8] pointed out that the burnability of the clinker of raw materials with less than $30 \%$ magnesium slag could be obviously improved. However, if the amount of magnesium slag in the raw materials was greater than $30 \%$, it would have a negative effect on the cement's properties such as decreasing the content of $\mathrm{C}_{3} \mathrm{~S}$, decreasing the compressive strength, and extending the setting time. Qiu et al. [9] prepared cement clinker by adding coal gangue and copper tailings to the raw materials as substitutes for natural clay. The results showed that qualified cement clinker could be obtained by adding coal gangue and copper tailings, and the calcining temperatures could also drop by $50-100^{\circ} \mathrm{C}$. However, the above studies primarily concentrated on a comparison of the clinker phases, burnability, and physical properties such as the consistency, setting time, soundness, flexural strength, and compressive strength of cement prepared with solid wastes and ordinary Portland cement. Few comparisons of the reaction mechanisms and hydration product types of cement prepared with solid wastes and ordinary Portland cement have been reported.

Ore tailings are the solid wastes produced by flotation [10-12], gravity concentration [13], and other separation of minerals [14]. Economic developments have greatly increased the demand for mineral products, as well as the scale of mining development $[15,16]$. China has produced more than 25 billion tons of ore tailings [17]. The discharge of ore tailings onto the earth's surface has caused an immeasurable impact on the environment $[18,19]$. Therefore, it is urgent to find an appropriate way to deal with ore tailings.

China's gold output ranks first in the world [20]. However, gold ore tailings have brought serious harm to the environment such as by occupying large quantities of farmland [21]. In order to alleviate this problem, some feasible solutions to transform gold ore tailings into an available resource have been explored by scholars. Liu et al. [22] systematically analyzed the chemical composition, mineral composition, particle size distribution, and other properties of gold ore tailings and found that gold ore tailings could be made into ceramic tiles and other ceramic products. Cao et al. [23] reported that gold ore tailings could be used as the raw materials of cemented tailings backfill. However, few studies have been performed on the application of gold ore tailings in the preparation of cement clinker. The production of Portland cement clinker requires a large amount of fine-grained siliceous materials, where the conventional siliceous materials used in the preparation of cement clinker are prepared by crushing and grinding sandstone to a specific level of granularity. The main component of gold ore tailings is silicon dioxide, and gold ore tailings have a very fine particle size [24], which is quite close to the requirements for the raw materials of cement plants. Thus, it is possible to use gold ore tailings as a siliceous raw material for the production of Portland cement.

The objective of this study was to prepare cement clinker using gold ore tailings with a high silica content as a substitute for natural sandstone and to analyze the feasibility of this substitution by comparing the mineralogical phases of the clinker, hydration products, and physical properties of the cement samples with and without gold ore tailings.

\section{Materials and Methods}

2.1. Materials. Raw materials containing limestone, bauxite, iron corrective material, and sandstone (SS) were collected from Fulaishan Cement Co., Ltd., Rizhao, Shandong Province, China. Their compositions are listed in Table 1.

The gold ore tailings (GTs) used in this study were collected from the Hexi Gold Mine Co., Ltd., Yan Tai, Shandong Province, China. Their chemical composition is also listed in Table 1.

The gypsum (AR99\%) in this study was provided by the Xiya Chemical Industry Co., Ltd., Shandong Province, China.

The XRD patterns of the GTs and SS are given in Figures 1 and 2 .

As shown in Figure 1, the GTs contained feldspar and mica, in addition to quartz, which indicated that the addition of GTs provided not only $\mathrm{SiO}_{2}$ but also a portion of $\mathrm{Al}_{2} \mathrm{O}_{3}$, and the total amount of bauxite in the raw materials of the cement clinker could also be partly reduced.

All of the raw materials in this exploratory experiment with two kinds of samples were ground via a millstone mill to avoid the adverse impact of too large a particle size on the process of calcining the cement clinker, especially the burnability of the raw materials. Figure 3 depicts the particle size distributions of the five materials used in the experiment. It could be found in Figure 3 that the maximum particle sizes of the limestone, bauxite, iron corrective material, SS, and GTs were $55.21 \mu \mathrm{m}, 60.54 \mu \mathrm{m}, 67.31 \mu \mathrm{m}$, $60.55 \mu \mathrm{m}$, and $67.51 \mu \mathrm{m}$, respectively.

2.2. Methods. The phase composition of ordinary Portland cement clinker is formed by the combination of two or more oxides at high temperature. Therefore, the effect on the mineral composition and properties of the cement clinker can be better reflected by controlling the clinker modulus (the ratio of various oxides) during the process of sintering the cement clinker rather than the contents of each oxide separately $[25,26]$. Accordingly, the clinker modulus of ordinary Portland cement was used as the control factor in this study. This modulus is shown in the following equations: 
TABLE 1: Chemical compositions of raw materials (wt.\%).

\begin{tabular}{lccccc}
\hline Materials & Limestone & Bauxite & $\begin{array}{c}\text { Iron corrective } \\
\text { material }\end{array}$ & SS & GTs \\
\hline $\mathrm{SiO}_{2}$ & 5.70 & 39.08 & 55.96 & 91.64 & 72.86 \\
$\mathrm{Al}_{2} \mathrm{O}_{3}$ & 1.17 & 33.77 & 2.09 & 3.15 & 13.68 \\
$\mathrm{Fe}_{2} \mathrm{O}_{3}$ & 0.42 & 11.13 & 35.32 & 1.69 & 1.11 \\
$\mathrm{CaO}$ & 48.26 & 0.85 & 1.87 & 0.34 & 1.06 \\
$\mathrm{MgO}$ & 2.81 & 1.34 & 3.89 & 0.37 & 0.08 \\
$\mathrm{SO}_{3}$ & 0.18 & 1.47 & 0.19 & 0.60 & 0.16 \\
$\mathrm{~K}_{2} \mathrm{O}$ & 0.35 & 0.25 & 0.03 & 0.20 & 5.32 \\
$\mathrm{Na}_{2} \mathrm{O}$ & 0.10 & - & 0.03 & 0.20 & 3.04 \\
$\mathrm{LOI}^{\mathrm{a}}$ & 40.87 & 11.72 & 0.47 & 1.11 & 1.98 \\
\hline
\end{tabular}

${ }^{\mathrm{a}}$ Loss on ignition at $950^{\circ} \mathrm{C}$.

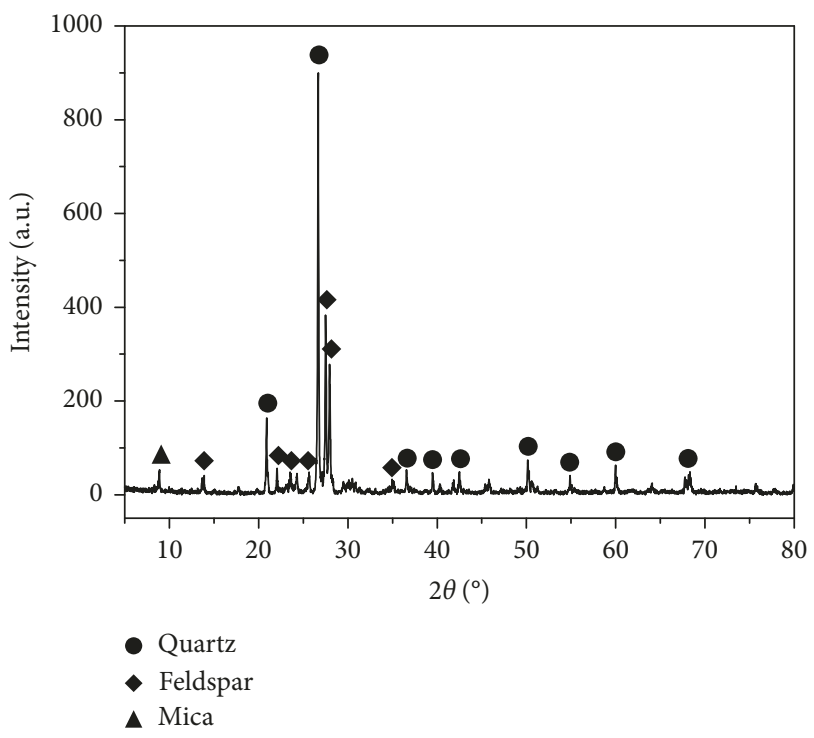

FIGURE 1: XRD pattern of GTs.

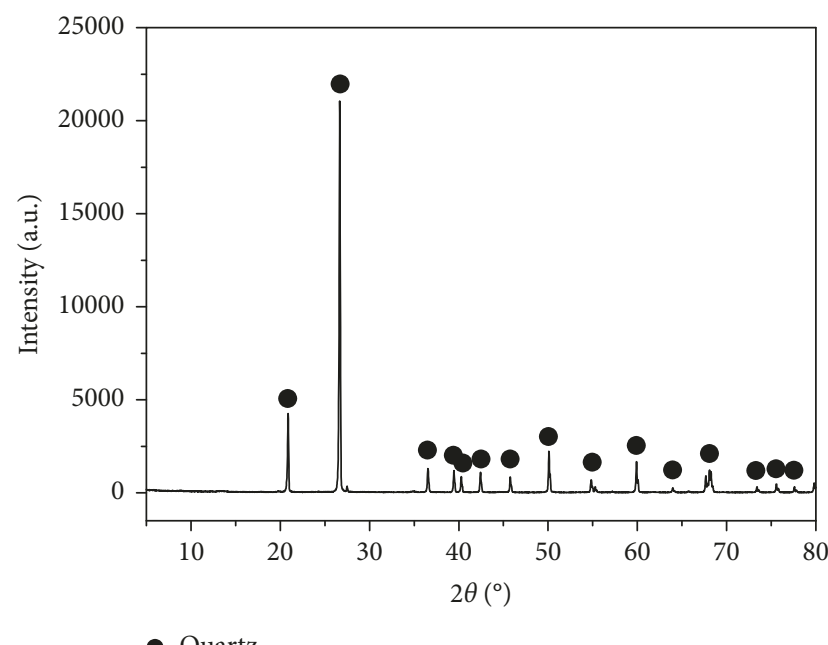

FIGURE 2: XRD pattern of SS.

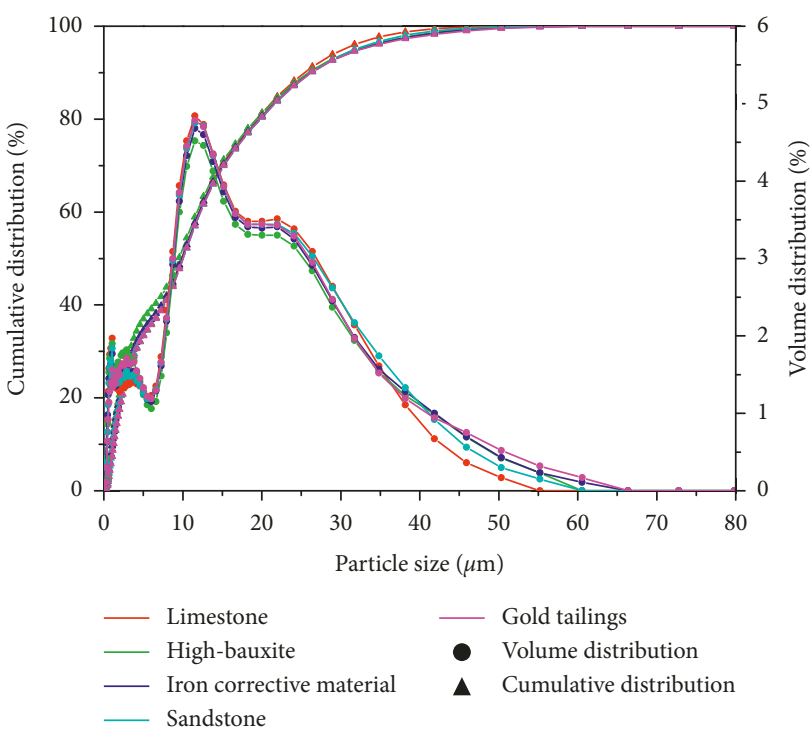

Figure 3: Particle size distributions of five raw materials.

lime saturation ratio $(\mathrm{KH})$

$$
=\frac{W(\mathrm{CaO})-1.65 \times W\left(\mathrm{Al}_{2} \mathrm{O}_{3}\right)-0.33 \times W\left(\mathrm{Fe}_{2} \mathrm{O}_{3}\right)}{2.8 \times W\left(\mathrm{SiO}_{2}\right)},
$$

silica modulus $(\mathrm{SM})=\frac{W\left(\mathrm{SiO}_{2}\right)}{W\left(\mathrm{Al}_{2} \mathrm{O}_{3}\right)+W\left(\mathrm{Fe}_{2} \mathrm{O}_{3}\right)}$,

alumina modulus $(\mathrm{IM})=\frac{W\left(\mathrm{Al}_{2} \mathrm{O}_{3}\right)}{W\left(\mathrm{Fe}_{2} \mathrm{O}_{3}\right)}$.

Two kinds of cement were manufactured under consistent circumstances for the parameters of the clinker modulus. One was prepared with GTs (C-GTs) and another was traditional Portland cement with SS (C-SS). The values of the lime saturation ratio $(\mathrm{KH})$, silica modulus (SM), and alumina modulus (IM) were $0.92,2.50$, and 1.60 , respectively. The proportions of raw materials in the two cement samples are listed in Table 2.

The thoroughly mixed raw material was packed into a cylindrical mold with a diameter of $50 \mathrm{~mm}$ and height of $30 \mathrm{~mm}$ at a pressure of $30 \mathrm{MPa}$ and then dried in a laboratory drying cabinet at $105^{\circ} \mathrm{C}$ for $2 \mathrm{~h}$. Subsequently, the samples were placed into a high-temperature muffle furnace (HTMF$1800-8)$ and heated from room temperature to $1500^{\circ} \mathrm{C}$ at a heating rate of $8^{\circ} \mathrm{C} / \mathrm{min}$ and kept burning for $60 \mathrm{~min}$. Then, the calcined cement clinker was immediately removed from the furnace, and its temperature was rapidly reduced to room temperature with the help of a fan to prevent the decomposition of $\mathrm{C}_{3} \mathrm{~S}$ and prevent the $\beta-\mathrm{C}_{2} \mathrm{~S}$ from transforming into $\gamma-\mathrm{C}_{2} \mathrm{~S}$ [27]. 
TABle 2: Proportions of raw materials in two cement samples (\%).

\begin{tabular}{lccccc}
\hline Samples & Limestone & Bauxite & $\begin{array}{c}\text { Iron corrective } \\
\text { material }\end{array}$ & SS & GTs \\
\hline C-SS & 85.79 & 6.28 & 2.53 & 5.41 & - \\
C-GTs & 85.36 & 3.79 & 3.29 & - & 7.56 \\
\hline
\end{tabular}

The calcined cement clinker was passed through a small jaw crusher and disc mill grinder until its specific surface area was $350 \pm 20 \mathrm{~m}^{2} / \mathrm{kg}$. Then, the ground clinker powder was thoroughly incorporated with $5 \%$ analytical gypsum $\left(\mathrm{CaSO}_{4} \cdot 2 \mathrm{H}_{2} \mathrm{O}\right)$.

A mortar experiment was performed in strict accordance with the relevant standards of Chinese National Standard GB/T 17671-1999, with a water-to-cement ratio of 0.5 and cement-to-sand ratio of $1: 3$. Then, the cement mortars were placed in a curing box until specific curing ages ( 3 days, 7 days, and 28 days) at a constant temperature $\left(20 \pm 1^{\circ} \mathrm{C}\right)$ and relative humidity ( $\geq 90 \%)$.

Paste experiment was also implemented referring to Chinese National Standard GB/T 17671-1999, with a waterto-cement ratio of 0.5 , which was used to study the hydration product types and microtopography at the curing ages of 3 and 28 days. The paste samples were cured under standard conditions (constant temperature: $20 \pm 1^{\circ} \mathrm{C}$; relative humidity: $\geq 90 \%$ ). Next, the paste samples of a specific age were crushed, and representative small fragments were selected and soaked in anhydrous ethanol for $72 \mathrm{~h}$ to terminate the hydration. These were reserved for a high-resolution scanning electron microscopy (SEM) test. The remaining samples were milled to a 200 mesh, and the hydration was terminated with anhydrous ethanol for X-ray diffraction (XRD) and thermogravimetric (TG) analyses.

The particle size distributions of the five raw materials were detected using a laser particle size analyzer (BT-9300Z).

The primary mineral phases of the GTs, SS, cement clinker, and hydration products of the cement paste terminated with anhydrous ethanol were measured based on the XRD (Rigaku Utima IV) with $\mathrm{Cu} \mathrm{Ka}$ radiation $(\lambda=1.5416 \AA)$ at a scanning speed of $5^{\circ} / \mathrm{min}$ operating at $40 \mathrm{kV}$ and $40 \mathrm{~mA}$ with a step of $0.02^{\circ}$.

The burnability of the cement's raw materials was tested based on Chinese National Standard GB/T 26566-2011.

The content of $\mathrm{f}-\mathrm{CaO}$ in cement clinker was analyzed based on Chinese National Standard GB/T 176-2008 (glycerol-ethanol method), and its value was the average of three sets of parallel samples.

The specific surface areas of the two kinds of cement clinker were measured based on Chinese National Standard GB/T 8074-2008 (Blaine method).

The mechanical tests of the cement mortar were carried out based on Chinese National Standard GB/T 17671-1999. The compressive strength value was the average of three values for each sample, and the flexural strength value was the average of two values for each sample.

The water requirement for a normal consistency, setting time, and soundness of the calcined cement was examined based on Chinese National Standard GB/T 1346-2011.
The TG (Mettler Toledo TGA2) analysis was implemented in a nitrogen atmosphere from $30^{\circ} \mathrm{C}$ to $900^{\circ} \mathrm{C}$ at a heating rate of $10^{\circ} \mathrm{C} / \mathrm{min}$.

The SEM (Nova Nano SEM450) analysis was conducted with an accelerating voltage of $10 \mathrm{kV}$.

\section{Results and Discussion}

3.1. Burnability of Cement Raw Materials. The burnability is an index relating to the content of $\mathrm{f}-\mathrm{CaO}$ (free lime) used to characterize the difficulty of forming cement clinker by calcining according to a certain calcining rule [7], with a lower $\mathrm{f}-\mathrm{CaO}$ content associated with better burnability of the raw meal. Figure 4 shows the $\mathrm{f}-\mathrm{CaO}$ contents of clinkers with SS and GTs at different temperatures.

As shown in Figure 4, the f-CaO contents of C-SS and C-GTs decreased with an increase in the temperature. It was the chemical reaction between fused $\mathrm{Ca}^{2+}$ and melted $\mathrm{SiO}_{4}{ }^{2-}$ at high temperature that consumed $\mathrm{f}-\mathrm{CaO}$. In other words, the $\mathrm{C}_{3} \mathrm{~S}$ content of the cement clinker mainly depended on the degree of reaction between $\mathrm{C}_{2} \mathrm{~S}$ and $\mathrm{f}-\mathrm{CaO}$ [9]. The chemical reaction at high temperature mentioned above could be exactly expressed by the following equation:

$$
\mathrm{C}_{2} \mathrm{~S}+\mathrm{CaO} \stackrel{\text { liquid phase }}{\longrightarrow} \mathrm{C}_{3} \mathrm{~S}
$$

It could also be seen in Figure 4 that the $\mathrm{f}-\mathrm{CaO}$ contents of clinkers with GTs at diverse temperatures were inferior to those of the clinkers with SS, which indicated that the burnability of the clinkers with GTs was superior to that of the clinkers with SS. This was because a mineral constituent with relatively high reactivity, such as the $\mathrm{Al}_{2} \mathrm{O}_{3}$ in GTs, played an important role, and a reaction between the $\mathrm{SiO}_{2}$ in the feldspar and $\mathrm{CaO}$ was more likely to occur than that between the $\mathrm{SiO}_{2}$ in the quartz and $\mathrm{CaO}$. Therefore, preparing a cement clinker with GTs was a better choice because of the reduction of the sintering temperature.

\subsection{Characterization of Clinkers}

3.2.1. XRD Analysis. The primary phase composition of the ordinary Portland cement includes $\mathrm{C}_{3} \mathrm{~S}, \mathrm{C}_{2} \mathrm{~S}, \mathrm{C}_{3} \mathrm{~A}$, and $\mathrm{C}_{4} \mathrm{AF}$ $[28,29]$. The XRD patterns of key mineralogical phases of the $\mathrm{C}$-SS and C-GTs after sintering at $1500^{\circ} \mathrm{C}$ are shown in Figure 5.

As shown in Figure 5, the mineralogical phases of the $\mathrm{C}$-SS and C-GTs were $\mathrm{C}_{3} \mathrm{~S}, \mathrm{C}_{2} \mathrm{~S}, \mathrm{C}_{3} \mathrm{~A}$, and $\mathrm{C}_{4} \mathrm{AF}$. The diffraction peaks of $\mathrm{C}_{3} \mathrm{~S}$ and $\mathrm{C}_{2} \mathrm{~S}$ were very stronger. In addition, there were no peaks of $\mathrm{f}-\mathrm{CaO}$ in XRD patterns because the contents of $\mathrm{f}-\mathrm{CaO}$ in two kinds of clinkers were much lower. Moreover, the intensity of diffraction peaks for the C-GTs was slightly higher than that for the C-SS. The results were in accordance with the burnability results, where the addition of GTs to the cement's raw materials could promote the formation of clinker phases under the same preparation conditions. The XRD analysis results showed that GTs could be used to prepare cement clinker. 


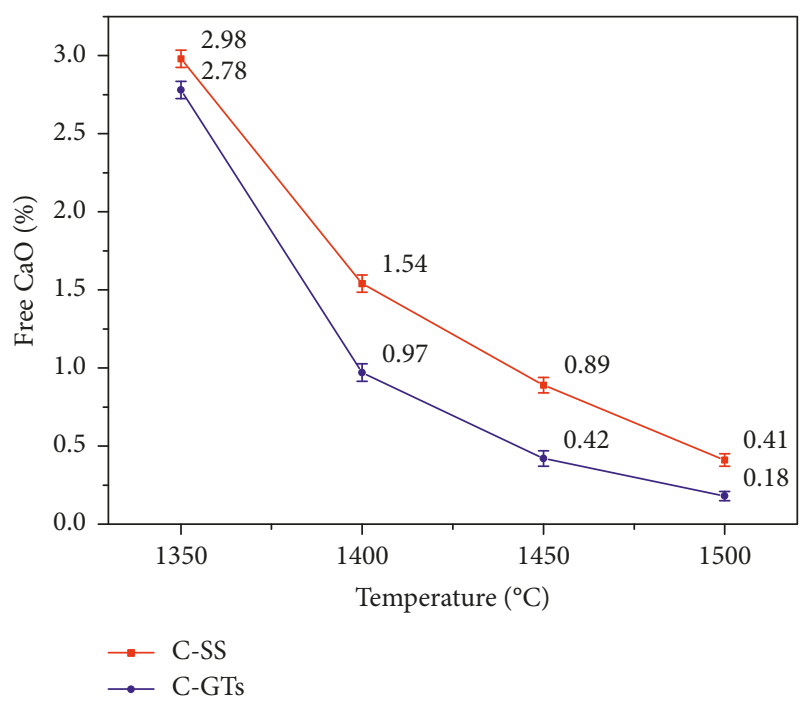

Figure 4: f-CaO contents of C-SS and C-GTs at different temperatures.

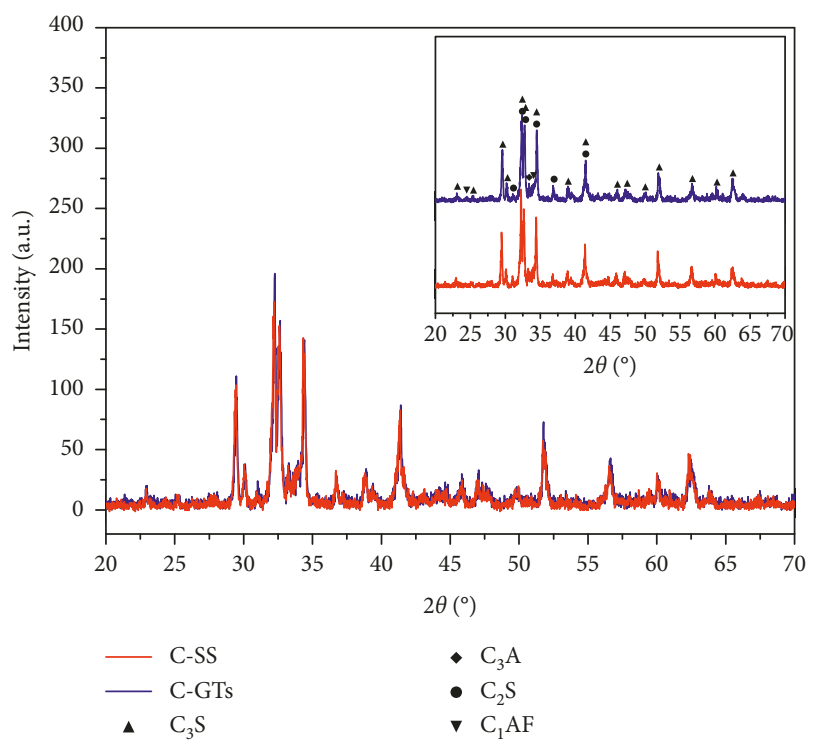

FIGURE 5: XRD patterns of cement clinkers.

3.2.2. Physical Properties of Cement Samples. Table 3 lists the physical indices of the two cements, including the specific surface, consistency, setting time, and soundness.

As shown in Table 3, the consistency and setting time values of the C-GTs and C-SS were almost the same in a case where the specific surface areas were the same, which indicated that the addition of GTs to the raw materials did not affect the consistency and setting time of the cement. Additionally, the soundness of both of them was qualified.

The flexural strength and compressive strength development of the C-GTs and C-SS with the curing time is given in Figure 6.

On one hand, as shown in Figure 6, the compressive and flexural strengths of the C-GTs and C-SS obviously increased with an increase in the curing time. On the other hand, the compressive and flexural strengths of the C-GTs at curing ages of 3 days (30.4 MPa and 6.1 MPa) and 28 days (59.1 MPa and $9.8 \mathrm{MPa}$ ) were slightly greater than those of the C-SS. The results demonstrated that the physical properties of C-GTs were in agreement with the 52.5 grade of cement's requirement according to the Chinese standard (GB/1752015).

\subsection{Hydration Products}

3.3.1. XRD Results. The XRD patterns of the cement pastes at curing ages of 3 and 28 days are given in Figure 7.

In Figure 7(a), it was easy to find the diffraction peaks of calcium hydroxide, ettringite, and the clinker phases $\left(\mathrm{C}_{3} \mathrm{~S}\right.$ and $\mathrm{C}_{2} \mathrm{~S}$ ) with a partial incomplete hydration reaction, with the exception of the calcium silicate hydrate gels, in the two kinds of pastes. The diffraction peaks of C-S-H gel were not detected because of the poor crystallization and amorphous properties of the C-S-H gel $[30,31]$.

With an increase in the curing age, the peak strength of each phase of the hydration products appeared to have a different trend. The diffraction peaks of primary cement phases such as $\mathrm{C}_{3} \mathrm{~S}$ and $\mathrm{C}_{2} \mathrm{~S}$ in the hydration products were significantly reduced with the extension of the curing age, indicating that the degree of hydration reaction was further deepened between tricalcium silicate/dicalcium silicate and water, and calcium silicate hydrate gels and calcium hydroxide were formed. Furthermore, it could be found in Figure $7(\mathrm{~b})$ that the diffraction peaks of the incompletely hydrated $\mathrm{C}_{3} \mathrm{~S}$ and $\mathrm{C}_{2} \mathrm{~S}$ in the C-GTs paste were lower than those in the C-SS paste at the same curing age. This small distinction indicated that the C-GTs was more prone to hydration under the same condition, and its flexural and compressive strengths were slightly higher than those of C-SS.

Therefore, the GTs did not affect the cement hydration and could be used to prepare Portland cement.

3.3.2. TG-DTG Analysis. The hydration products of the pastes were also validated using the TG technique and derivative thermogravimetry (DTG) technique. Their TG/ DTG curves at the curing ages of 3 days and 28 days are given in Figure 8.

The first major dehydration peaks in the DTG curves (Figure 8(b)) were for the C-S-H gel and ettringite. Based on a previous report [32], the peak section from $50^{\circ} \mathrm{C}$ to $200^{\circ} \mathrm{C}$ was not only for the $\mathrm{C}-\mathrm{S}-\mathrm{H}$ gels but also for the ettringite phase. Therefore, it was difficult to find an obvious distinction between the dehydration temperatures for the C$\mathrm{S}-\mathrm{H}$ gels and ettringite phase. Additionally, the weight-loss percentages (Figure 8(a)) of the C-SS and C-GTs pastes visibly increased at the curing age of 28 days compared to those at the curing age of 3 days, and the intensities of the first major dehydration peaks in the DTG curves (Figure 8(b)) were apparently enhanced at the curing age of 28 days compared to those at the curing age of 3 days in this temperature range. These results indicated that the hydration degree was further deepened, more $\mathrm{C}_{3} \mathrm{~S}, \mathrm{C}_{2} \mathrm{~S}$, and 
TABLE 3: Physical indices of two cements.

\begin{tabular}{|c|c|c|c|c|c|}
\hline \multirow{2}{*}{ Samples } & \multirow{2}{*}{ Specific surface $\left(\mathrm{m}^{2} / \mathrm{kg}\right)$} & \multirow{2}{*}{ Consistency (\%) } & \multicolumn{2}{|c|}{ Setting time $(\mathrm{min})$} & \multirow{2}{*}{ Soundness } \\
\hline & & & Initial time & Final time & \\
\hline C-SS & 355.4 & 24.5 & 140 & 212 & Qualified \\
\hline C-GTs & 355.9 & 24.8 & 138 & 215 & Qualified \\
\hline
\end{tabular}

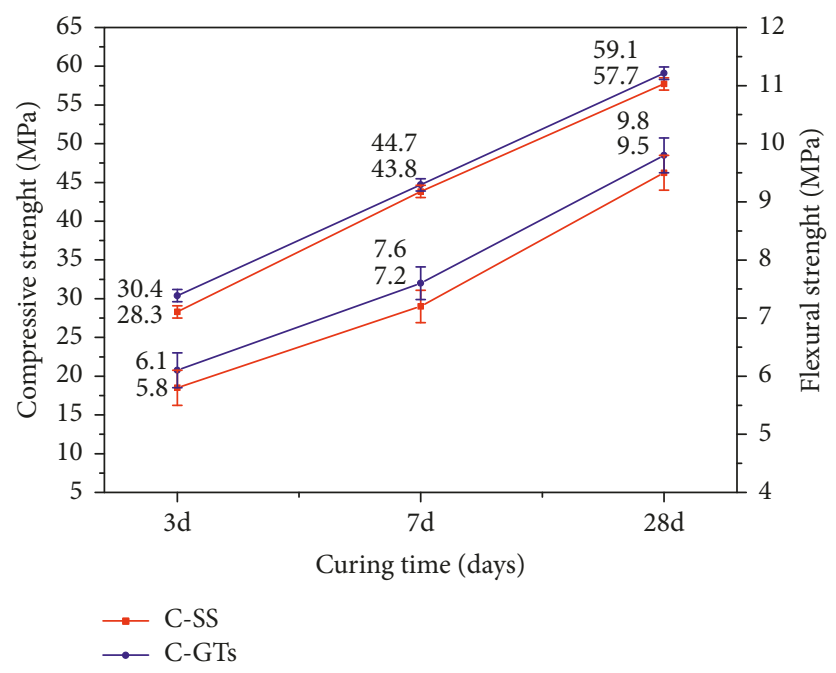

Figure 6: Compressive and flexural strengths of two cements with curing days.

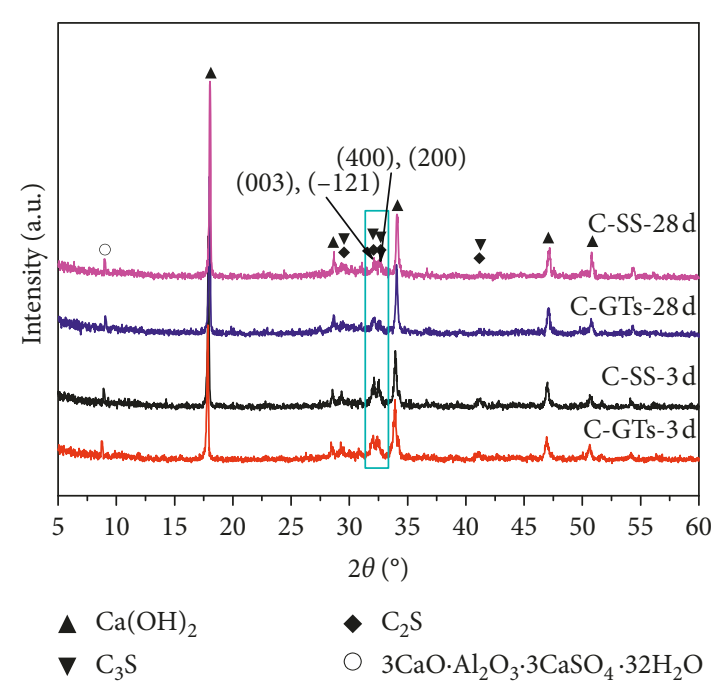

(a)

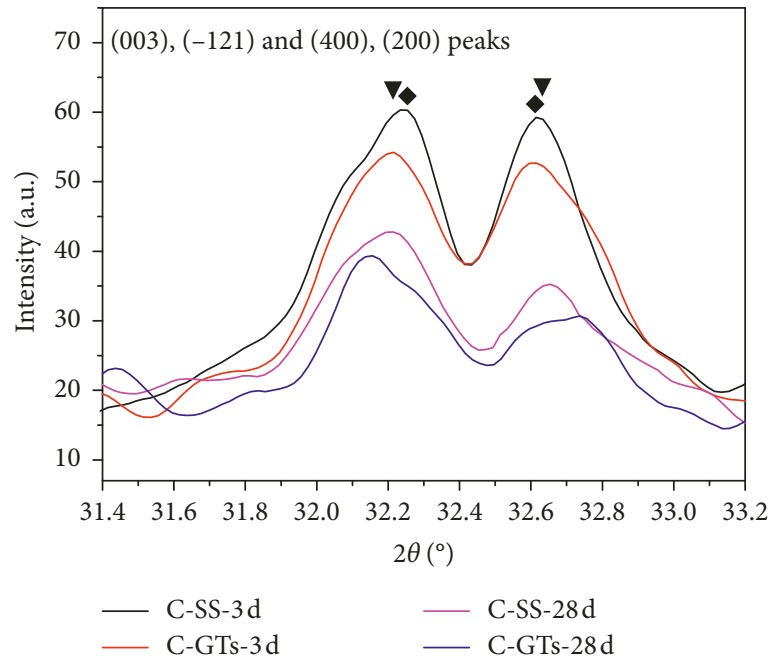

(b)

FIGURE 7: XRD patterns of pastes after 3 days and 28 days.

gypsum were consumed, and more $\mathrm{C}-\mathrm{S}-\mathrm{H}$ gel and ettringite were generated.

The second major dehydration peak between $400^{\circ} \mathrm{C}$ and $500^{\circ} \mathrm{C}$ in each of the DTG curves (Figure $8(\mathrm{~b})$ ) was attributed to the decomposition of calcium hydroxide [33]. Tricalcium silicate and dicalcium silicate reacted with water to form $\mathrm{C}-\mathrm{S}-\mathrm{H}$ gels and calcium hydroxide [34]. The intensities of the C-SS and C-GTs paste samples at the curing age of 28 days were stronger than those at the curing age of 3 days, which indicated that the hydration degree was also further deepened with the extension of the curing age.

The third major dehydration peak between $600^{\circ} \mathrm{C}$ and $700^{\circ} \mathrm{C}$ was ascribed to the decomposition of carbonatecontaining phases. The carbonation of the sectional calcium hydroxide and segmental $\mathrm{C}-\mathrm{S}-\mathrm{H}$ gel accounted for $70-80 \%$ of the carbonate-containing phases [35]. In addition, some phases containing calcium (tricalcium silicate and dicalcium silicate) were also prone to carbonization 


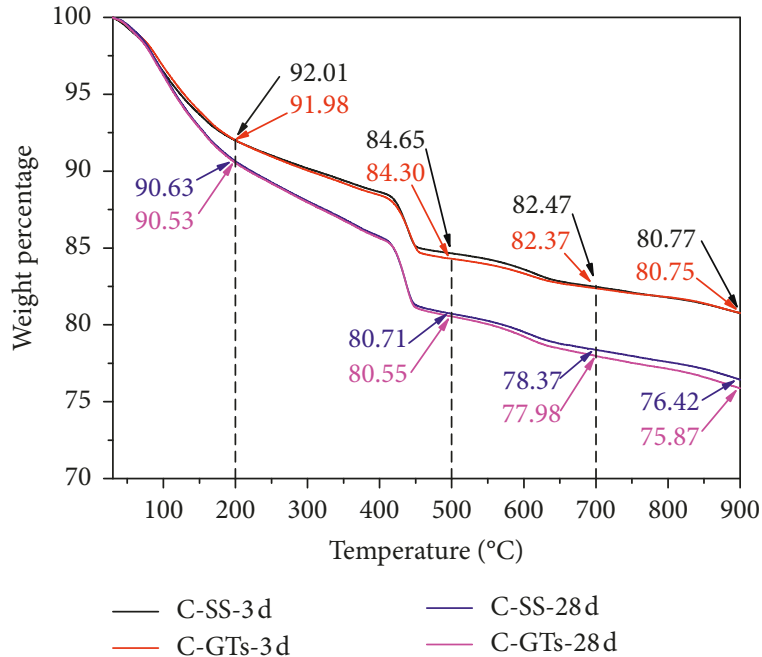

(a)

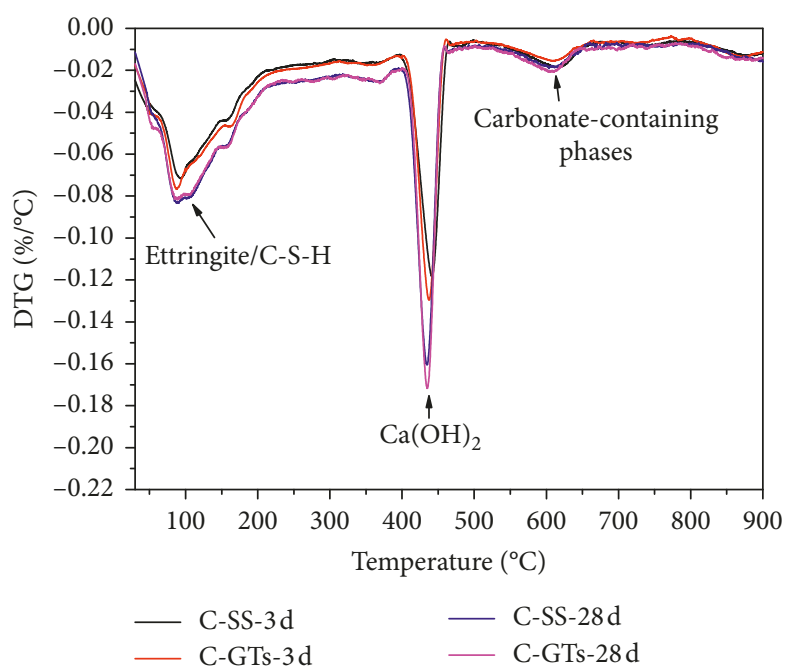

(b)

Figure 8: TG/DTG curves of pastes at curing ages of 3 days and 28 days.

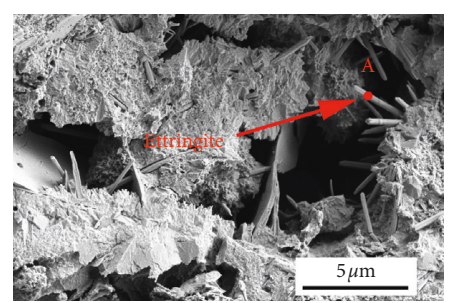

(a)
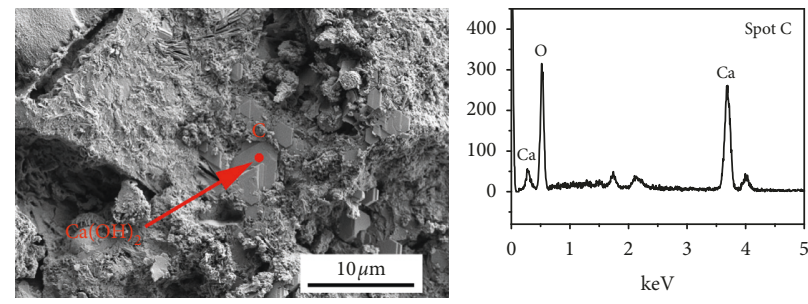

(c)
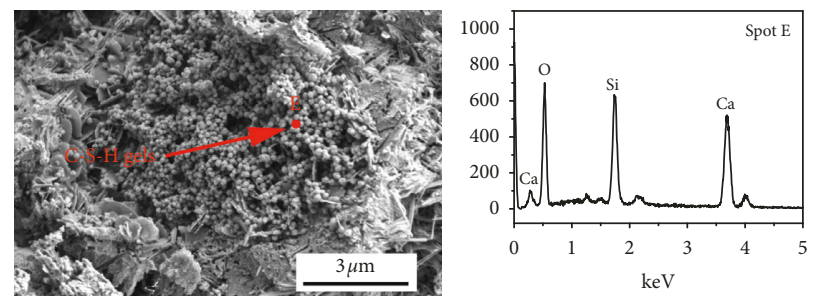

(e)

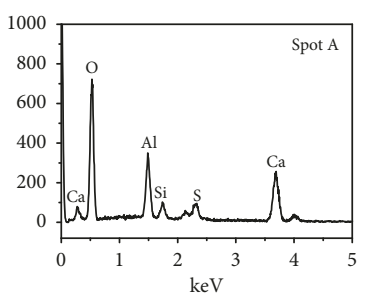

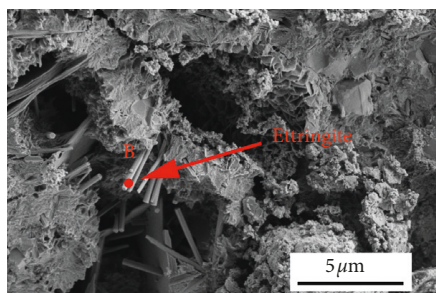

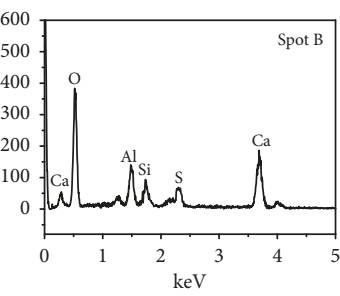

(b)
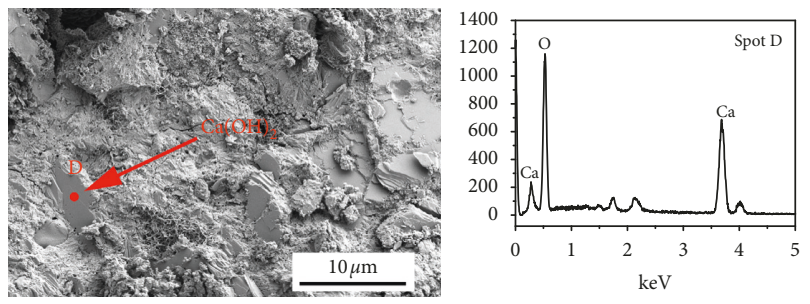

(d)
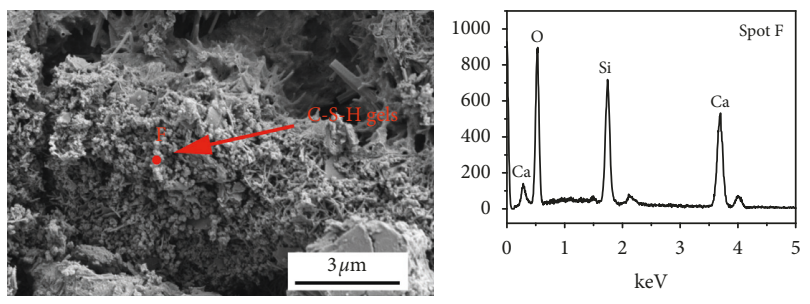

(f)

Figure 9: SEM images and EDS analysis results for C-SS paste ((a), (c), and (e)) and C-GTs paste ((b), (d), and (f)) at age of 28 days.

[36]. It was found that the four DTG curves (Figure 8(b)) almost overlapped completely at a temperature range of $600-700^{\circ} \mathrm{C}$, indicating that the numbers of carbonatecontaining phases were almost equal.

The slight weight-loss difference in the TG curves of Figure 8(a) was due to the hydration rate of the C-GTs paste being faster than that of the C-SS paste, which indicated that the compressive strength and flexural strength of the C-GTs were slightly higher than those of the C-SS.

The TG analysis results were in accordance with the XRD analysis results and further confirmed the feasibility of preparing cement clinker with GTs. 
3.3.3. SEM-EDS Analysis. The SEM-EDS results for the hydration products of the C-SS and C-GTs paste samples at a curing age of 28 days are shown in Figure 9.

Based on the SEM-EDS analysis, it could be concluded that there were some rod-shaped ettringite crystals (Figures 9(a) and 9(b)), flaky calcium hydroxide crystals (Figures 9(c) and 9(d)), and a granular C-S-H gel phase (Figures 9(e) and 9(f)) in the C-SS paste and C-GTs paste at the curing age of 28 days. The existence of these special structures greatly contributed to the macroscopic physical properties. Thus, it was found on the macrolevel that various physical properties such as the flexural strength and compressive strength of the C-GTs reached the requirements of P.I 52.5. Furthermore, the results were considerably consistent with the XRD and TG analysis results.

\section{Conclusions}

This study investigated the feasibility of preparing cement with GTs. The main conclusions are as follows:

(i) The GTs could improve the burnability of raw materials due to its relatively high reactivity. Furthermore, it did not affect the clinker mineralogical phases and types of hydration products.

(ii) C-GTs performed well in macroscopic physical properties. Its consistency, initial setting time, and final setting time were similar to those of ordinary Portland cement. Additionally, its compressive strength and flexural strength were, respectively, $59.1 \mathrm{MPa}$ and $9.8 \mathrm{MPa}$ at the curing age of 28 days.

(iii) The utilization of GTs in cement preparation was beneficial for supply and cost problems of cement raw materials and disposal of GTs.

\section{Data Availability}

The data used to support the findings of this study are included within the article.

\section{Additional Points}

Gold ore tailings were used as a siliceous raw material for cement production. The clinker mineralogical phases and cement's hydration products were not affected by gold ore tailings. The burnability of cement raw materials was improved by gold ore tailings. Statement of novelty: gold ore tailings are the solid wastes produced by mineral separation, and their disposal has been a difficult problem. This study investigated the feasibility of preparing cement with gold ore tailings by comparing the mineralogical phases of the clinker and hydration product types, along with the physical properties of cement prepared with gold ore tailings and ordinary Portland cement with sandstone. The results showed that the mineralogical phases of cement prepared with gold ore tailings were $\mathrm{C}_{3} \mathrm{~S}, \mathrm{C}_{2} \mathrm{~S}, \mathrm{C}_{3} \mathrm{~A}$, and $\mathrm{C}_{4} \mathrm{AF}$, and its hydration products were rod-shaped ettringite crystals, flaky calcium hydroxide crystals, and a granular C-S-H gel phase.
This paper provided a feasible approach for the disposal of gold ore tailings.

\section{Conflicts of Interest}

The authors declare that they have no conflicts of interest.

\section{Acknowledgments}

This work was supported by the Natural Science Foundation of China (No. 51674161), Major Program of Shandong Province Natural Science Foundation (No. ZR2017ZC0735), and the Introduction of Talent Research Start-up Fund of Shandong University of Science and Technology, China (No. 2017RCJJ036).

\section{References}

[1] C. Li, Z. Nie, S. Cui, X. Gong, Z. Wang, and X. Meng, "The life cycle inventory study of cement manufacture in China," Journal of Cleaner Production, vol. 72, pp. 204-211, 2014.

[2] A. C. Bourtsalas, J. Zhang, M. J. Castaldi, and N. J. Themelis, "Use of non-recycled plastics and paper as alternative fuel in cement production," Journal of Cleaner Production, vol. 181, pp. 8-16, 2018.

[3] Q. Wu, Y. Wu, W. Tong, and H. Ma, "Utilization of nickel slag as raw material in the production of Portland cement for road construction," Construction and Building Materials, vol. 193, pp. 426-434, 2018.

[4] M. Huang, H. Feng, N. Li, D. Shen, Y. Zhou, and Y. Jia, "Addition of large amount of municipal sewage sludge as raw material in cement clinker production," Environmental Science and Pollution Research, vol. 24, no. 36, pp. 27862-27869, 2017.

[5] G. Young and M. Yang, "Preparation and characterization of Portland cement clinker from iron ore tailings," Construction and Building Materials, vol. 197, pp. 152-156, 2019.

[6] A. S. D. Vilaplana, V. J. Ferreira, A. M. López-Sabirón et al., "Utilization of Ladle Furnace slag from a steelwork for laboratory scale production of Portland cement," Construction and Building Materials, vol. 94, pp. 837-843, 2015.

[7] L. Luo, Y. Zhang, S. Bao, and T. Chen, "Utilization of iron ore tailings as raw material for Portland cement clinker production," Advances in Materials Science and Engineering, vol. 2016, Article ID 1596047, 6 pages, 2016.

[8] H. Li, Y. Huang, X. Yang, Z. Jiang, and Z. Yang, "Approach to the management of magnesium slag via the production of Portland cement clinker," Journal of Material Cycles and Waste Management, vol. 20, no. 3, pp. 1701-1709, 2018.

[9] G. Qiu, Z. Luo, Z. Shi, and M. Ni, "Utilization of coal gangue and copper tailings as clay for cement clinker calcinations," Journal of Wuhan University of Technology-Mater. Sci. Ed., vol. 26, no. 6, pp. 1205-1210, 2011.

[10] Q. Feng, S. Wen, J. Deng, and W. Zhao, "Combined DFT and XPS investigation of enhanced adsorption of sulfide species onto cerussite by surface modification with chloride," Applied Surface Science, vol. 425, pp. 8-15, 2017.

[11] Q. Feng, W. Zhao, S. Wen, and Q. Cao, "Activation mechanism of lead ions in cassiterite flotation with salicylhydroxamic acid as collector," Separation and Purification Technology, vol. 178, pp. 193-199, 2017.

[12] Q. Feng, W. Zhao, and S. Wen, "Surface modification of malachite with ethanediamine and its effect on sulfidization flotation," Applied Surface Science, vol. 436, pp. 823-831, 2018. 
[13] Y. Zhao, Y. Zhang, T. Liu, T. Chen, Y. Bian, and S. Bao, "Preconcentration of vanadium from stone coal by gravity separation," International Journal of Mineral Processing, vol. 121, pp. 1-5, 2013.

[14] X. Zhang, X. Tan, Y. Yi, W. Liu, and C. Li, "Recovery of manganese ore tailings by high-gradient magnetic separation and hydrometallurgical method," JOM, vol. 69, no. 11, pp. 2352-2357, 2017.

[15] J. L. B. Galvão, H. D. Andrade, G. J. Brigolini, R. A. F. Peixoto, and J. C. Mendes, "Reuse of iron ore tailings from tailings dams as pigment for sustainable paints," Journal of Cleaner Production, vol. 200, pp. 412-422, 2018.

[16] G. Yao, Q. Liu, J. Wang, P. Wu, and X. Lyu, "Effect of mechanical grinding on pozzolanic activity and hydration properties of siliceous gold ore tailings," Journal of Cleaner Production, vol. 217, pp. 12-21, 2019.

[17] C. Qi, A. Fourie, Q. Chen, X. Tang, Q. Zhang, and R. Gao, "Data-driven modelling of the flocculation process on mineral processing tailings treatment," Journal of Cleaner Production, vol. 196, pp. 505-516, 2018.

[18] W. Sun, H. Wang, and K. Hou, "Control of waste rock-tailings paste backfill for active mining subsidence areas," Journal of Cleaner Production, vol. 171, pp. 567-579, 2018.

[19] S. Panchal, D. Deb, and T. Sreenivas, "Mill tailings based composites as paste backfill in mines of U-bearing dolomitic limestone ore," Journal of Rock Mechanics and Geotechnical Engineering, vol. 10, no. 2, pp. 310-322, 2018.

[20] W. Chen, Y. Geng, J. Hong et al., "Life cycle assessment of gold production in China," Journal of Cleaner Production, vol. 179, pp. 143-150, 2018.

[21] G. Olivier, T. de Wit, F. Brenguier, L. Bezuidenhout, and T. Kunjwa, "Ambient noise Love wave tomography at a gold mine tailings storage facility," Géotechnique Letters, vol. 8, no. 3, pp. 178-182, 2018.

[22] R. Liu, F. Huang, R. Du, C. Zhao, Y. Li, and H. Yu, "Recycling and utilisation of industrial solid waste: an explorative study on gold deposit tailings of ductile shear zone type in China," Waste Management and Research, vol. 33, no. 6, pp. 570-577, 2015.

[23] S. Cao, E. Yilmaz, and W. D. Song, "Evaluation of viscosity, strength and microstructural properties of cemented tailings Backfill," Minerals, vol. 8, no. 8, 2018.

[24] D. Q. Deng, L. Liu, Z. L. Yao, K. I.-I. L. Song, and D. Z. Lao, “A practice of ultra-fine tailings disposal as filling material in a gold mine," Journal of Environmental Management, vol. 196, pp. 100-109, 2017.

[25] H. Cao, W. Liu, J. Xu et al., "Utilization of lime-dried sludge for eco-cement clinker production: effects of different feeding points," Water Science and Technology, vol. 77, no. 4, pp. 960-970, 2018.

[26] Y. Lin, S. Zhou, F. Li, and Y. Lin, "Utilization of municipal sewage sludge as additives for the production of eco-cement," Journal of Hazardous Materials, vol. 213-214, pp. 457-465, 2012.

[27] C. H. K. Lam, J. P. Barford, and G. Mckay, "Utilization of municipal solid waste incineration ash in Portland cement clinker," Clean Technologies and Environmental Policy, vol. 13, no. 4, pp. 607-615, 2011.

[28] F. Dunstetter, M. N. D. Noirfontaine, and M. Courtial, "Polymorphism of tricalcium silicate, the major compound of Portland cement clinker: 1 . Structural data: review and unified analysis," Cement and Concrete Research, vol. 36, no. 1, pp. 54-64, 2006.

[29] P. E. Tsakiridis, S. Agatzini-Leonardou, and P. Oustadakis, "Red mud addition in the raw meal for the production of
Portland cement clinker," Journal of Hazardous Materials, vol. 116, no. 1-2, pp. 103-110, 2004.

[30] P. E. Tsakiridis, P. Oustadakis, and S. Agatzini-Leonardou, "Black dross leached residue: an alternative raw material for Portland cement clinker," Waste and Biomass Valorization, vol. 5, no. 6, pp. 973-983, 2014.

[31] İ. Alp, H. Deveci, E. Y. Yazıc1, T. Türk, and Y. H. Süngün, "Potential use of pyrite cinders as raw material in cement production: results of industrial scale trial operations," Journal of Hazardous Materials, vol. 166, no. 1, pp. 144-149, 2009.

[32] E. Qoku, T. A. Bier, and T. Westphal, "Phase assemblage in ettringite-forming cement pastes: a X-ray diffraction and thermal analysis characterization," Journal of Building Engineering, vol. 12, pp. 37-50, 2017.

[33] P. E. Tsakiridis, M. Samouhos, and M. Perraki, "Valorization of Dried Olive Pomace as an alternative fuel resource in cement clinkerization," Construction and Building Materials, vol. 153, pp. 202-210, 2017.

[34] E. Gartner, I. Maruyama, and J. Chen, "A new model for the $\mathrm{C}-\mathrm{S}-\mathrm{H}$ phase formed during the hydration of Portland cements," Cement and Concrete Research, vol. 97, pp. 95-106, 2017.

[35] Y. Fang and J. Chang, "Microstructure changes of waste hydrated cement paste induced by accelerated carbonation," Construction and Building Materials, vol. 76, pp. 360-365, 2015.

[36] B. Šavija and M. Luković, "Carbonation of cement paste: understanding, challenges, and opportunities," Construction and Building Materials, vol. 117, pp. 285-301, 2016. 


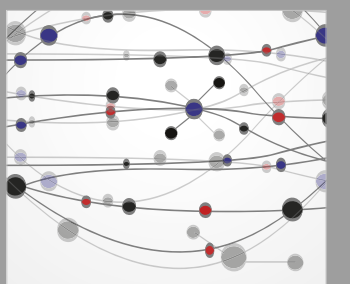

The Scientific World Journal
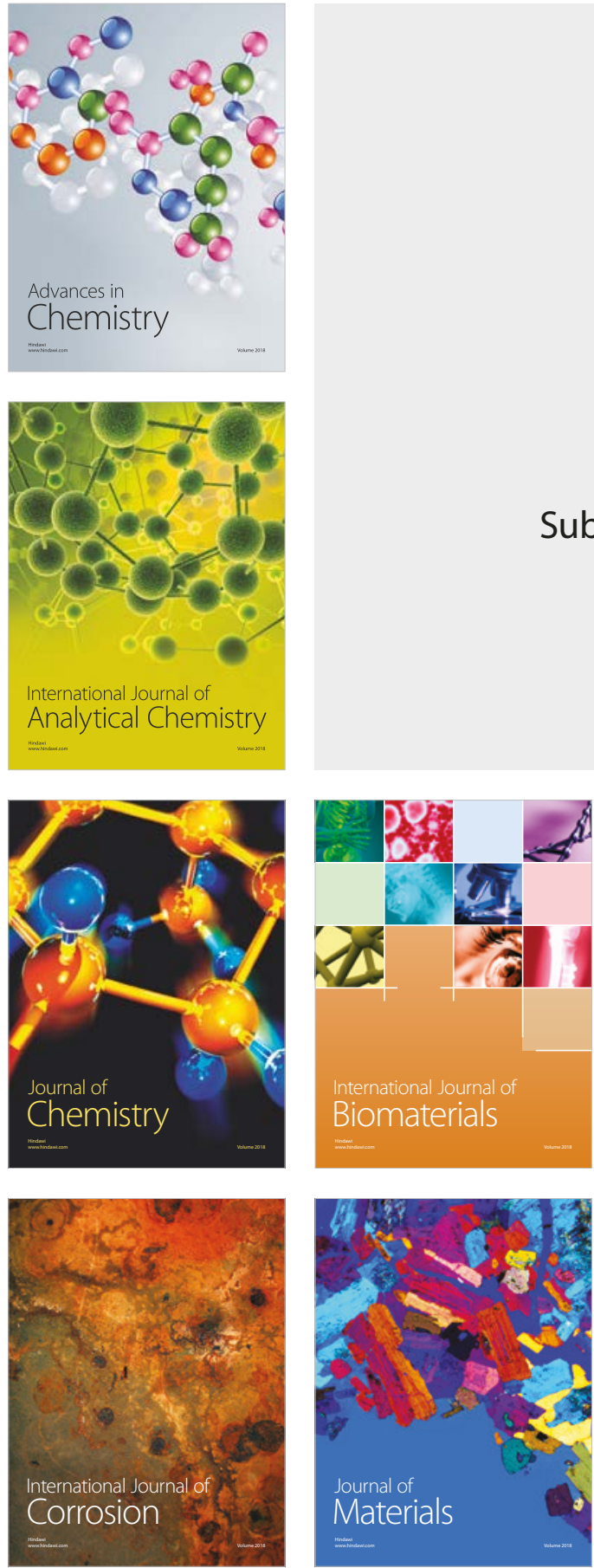

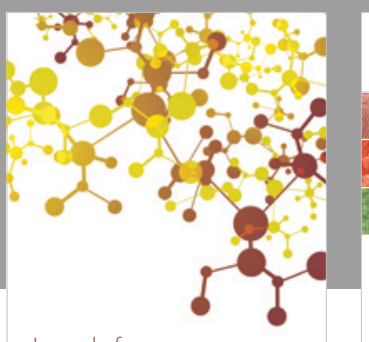

Journal of

Applied Chemistry
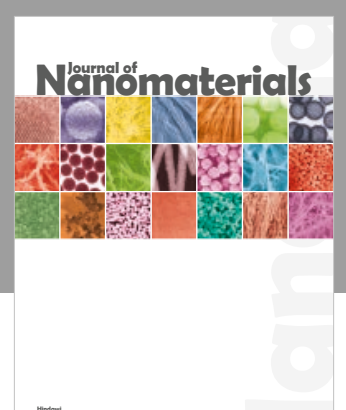

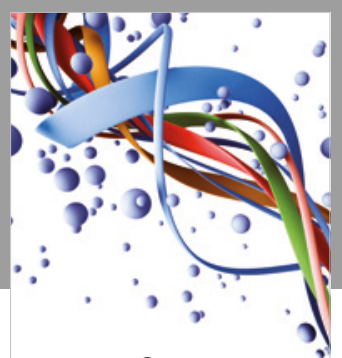

Scientifica

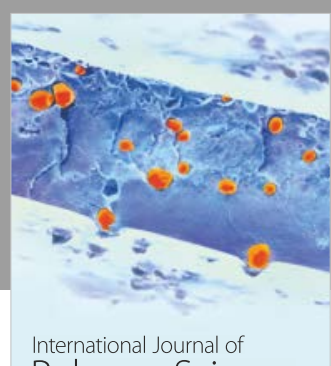

Polymer Science

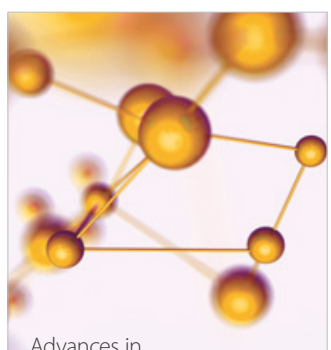

Physical Chemistry
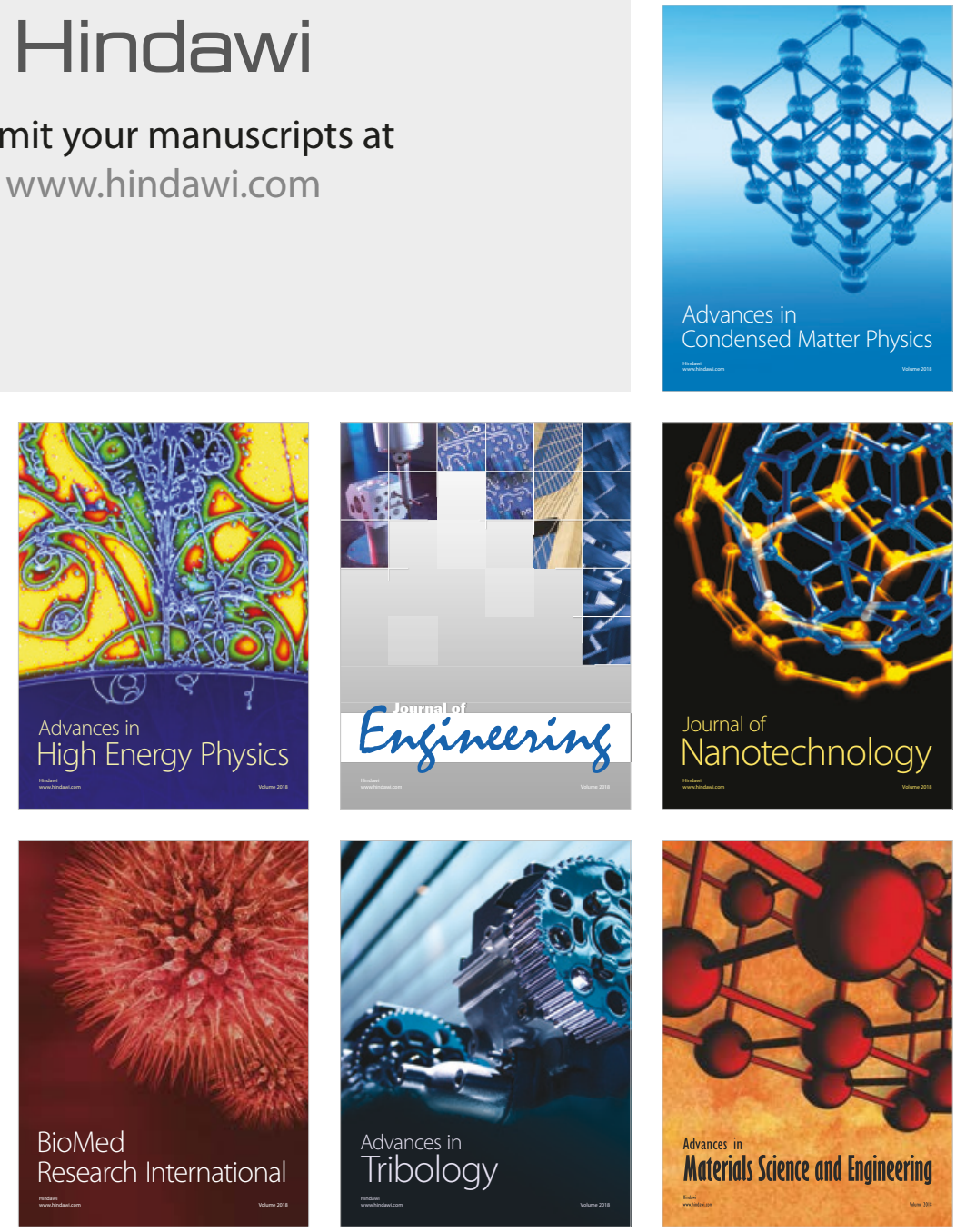